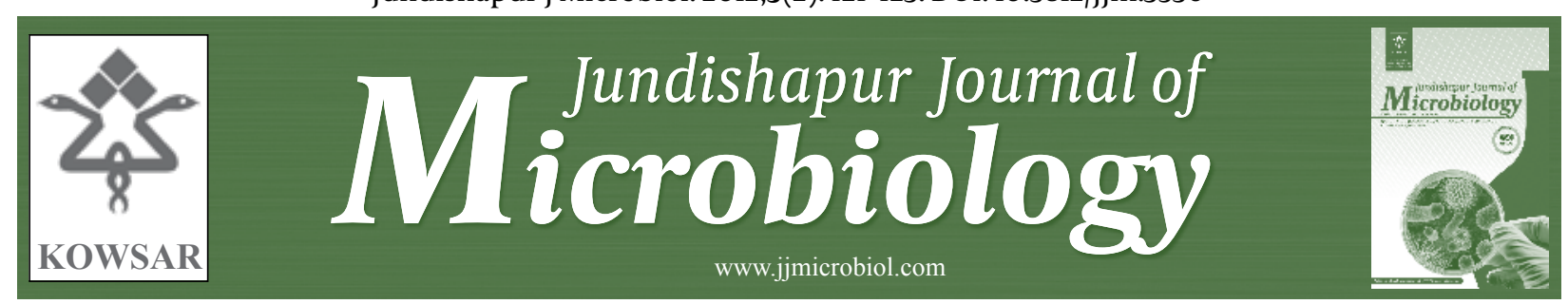

\title{
Comparison the Radiologic Findings of Pulmonary Tuberculosis Among HIV-Seropositive With HIV-Seronegative Patients
}

\author{
Fatmeh Ahmadi ${ }^{1,2^{*}}$, Shokrollah Salmanzadeh ${ }^{1}$, Mehdi Kimyai ${ }^{3}$ \\ ${ }^{1}$ Razi Hospital, Ahvaz Jundishapur University of Medical Sciences, Ahvaz, IR Iran \\ ${ }^{2}$ Research Center of Infectious Diseases and Tropical Medicine, Ahvaz Jundishapur University of Medical Sciences, Ahvaz, IR Iran \\ ${ }^{3}$ Emergency Department, Razi Hospital, Ahvaz Jundishapur University of Medical Sciences, Ahvaz, IR Iran \\ A R T I C L E I N F O \\ A B S T R A C T
}

Article type:

Original Article

Article history:

Received: 01 Jun 2010

Revised:01 Oct 2011

Accepted:01 Nov 2011

\section{Keywords:}

Tuberculosis

HIV-seropositive

Tuberculosis

Radiological Health

\begin{abstract}
Background: Approximately1.8 million of the world's population is infected with both M.tuberculosis (TB) and HIV.HIV-seropositive patients with TB may have radiographically atypical presentations. objectives: This study aimed to determine whether there was any difference in radiological presentation of pulmonary TB between HIV-seropositive and HIV-seronegative patients.

Patients and Methods: Information on 204 patients who were admitted with a diagnosis of pulmonary TB to the infectious ward of Razi Hospital, Ahvaz, between 2004 and 2008 was obtained from their records. They were divided into HIV-seropositive and HIV-seronegative groups. All clinical signs and symptoms and radiological findings were extracted from each patient file and recorded in a questionnaire.

Results: Normal thoracic radiography, pleural effusion, milliary pattern, and hilar and mediastinal lymphadenopathy were more common in the HIV-seropositive group. Pulmonary infiltration and cavitary lesions in Chest X-ray (CXR) were more frequent in the HIV-seronegative group. The prevalence of fibrosis in HIV-seronegative patients was higher than in HIV-seropositive subjects. Upper lobe pulmonary involvement in HIV-seropositive patients was less frequent than HIV-seronegative persons due to their immunodeficiency.

Conclusions: Radiological presentation of pulmonary TB differs between HIV-seropositive and HIV-seronegative patients due to progressive immunodeficiency from HIV infection.
\end{abstract}

Copyright @ 2012 Kowsar Corp. All rights reserved.

- Implication for health policy/practice/research/medical education:

As pulmonary tuberculosis is an important opportunistic infection in patients with advanced HIV infection, delay in diagnosis and treatment may lead to severe morbidity and death. So clinicians should be aware about different and sometimes atypical radiographic manifestations of pulmonary tuberculosis in HIV infected patients. The importance of this study is to define such atypical.

- Please cite this paper as:

Ahmadi F, Salmanzadeh S, Kimyai M, Comparison the Radiologic Findings of Pulmonary Tuberculosis Among HIV-Seropositive With HIV-Seronegative Patients. JundishapurJ Microbiol.2012;5(2):421-3. DOI: 10.5812/jjm.3536

\section{Background}

It was widely believed that tuberculosis (TB) was controlled at least in developed countries, but in the 1980s, the incidence of this disease increased dramatically (1). The cause of this phenomenon was the epidemic HIV infection and the coexistence of these 2 diseases. In the

${ }^{*}$ Corresponding author: Fatmeh Ahmadi, Razi Hospital, Ahvaz Jundishapur University of medical sciences, Ahvaz, IR Iran. Tel: +98-6113335935; Fax:+98-6115551757, E-mail: dr_Ahmadi031@yahoo.com

DOI:10.5812/jjm.3536

Copyright $\odot 2012$ Kowsar Corp. All rights reserved.
United States, the incidence of TB declined due to its control of HIV (Human Immuno deficiency Virus) infection (1). The incidence of TB in developing countries increased due to the presence of TB in patients with HIV infection and endemicity of TB. More than 95\% of cases of TB infection and concurrent HIV occur in developing countries (2). HIV-infected patients are predisposed not only to reactivation of remote infection but also to rapid progression of recently acquired infections (1).

Approximately 1.8 million of the world's population is infected with both diseases, and $22 \%$ of deaths due to TB infection occur in TB-HIV coinfected patients (1). The 
likelihood of progression of latent TB to active TB in HIVseropositive patients is $5 \%$ to $15 \%$ per year or $30 \%$ during their lifetime versus $5 \%$ to $10 \%$ of HIV-seronegative people during their lifetime $(2,3)$. In a study by Alavi et al. (4), pulmonary TB was present in $45 \%$ of HIV-positive addicts. Chest X-ray (CXR) is central to the diagnosing tuberculosis, determining the extent and character of disease, and evaluating the response to therapy (1).

Because the radiographic presentation of tuberculosis depends on the severity of immune system reactions and the number of bacilli in the lung, such characteristics should differ between patients with HIV and TB (5). Therefore, HIV-seropositive patients may have radiographically atypical presentations (6). This study aimed to determine whether there are differences in the radiological presentation of pulmonary TB between HIV-seropositive and HIV-seronegative patients.

\section{Patients and Methods}

This descriptive epidemiological retrospective study was based on hospital information. The study population included all patients with pulmonary TB who were hospitalized in the infectious ward of Razi Hospital, Ahvaz, Iran, from 2004 to 2008 . The sampling method was non-random and targeted. After studying the records of patients, we divided them into HIV-seropositive and HIV-seronegative groups. The required information, including all clinical signs and symptoms and radiological findings, was extracted from each patient file and recorded in a questionnaire.

Inclusion criteria, per the WHO (World Health Organization) definition, were having at least 1 of the following criteria: clinical signs with repeat sputum smear-positive acid-fast bacilli, clinical signs with a positive sputum smear and sputum culture, clinical signs with a positive sputum smear in patients with a chest X-ray that was suggestive of pulmonary TB that was detected by a clinician or radiologist. HIV diagnostic criteria were having a 2 positive ELISA tests and a positive western blot (7). Exclusion criteria included files that were missing relevant information and HIV-seronegative persons who were immunocompromised for any reason.

\subsection{Statistical Analysis}

The data were analyzed with SPSS 13.0. Statistical comparison of variables was performed using chi-square test. $P$-values less than 0.05 were considered significant.

\section{Results}

In this study, 204 patients with pulmonary TB were evaluated; 170 cases were HIV- seronegative and 34 cases were HIV-seropositive. The mean $( \pm \mathrm{SD})$ age in the HIV-seropositive and HIV- seronegative groups was $31.85 \pm 8.52$ and $44.33 \pm 10.34$ years, respectively $(P=0.001)$. All HIVseropositive patients were male, and the HIV-seronega- tive group comprised 120 (70.6\%) males and 50 (29.4\%) females $(P<0.001)$.

Eleven (32.35\%) HIV-seropositive patients and 20 (11.76\%) HIV-seronegative patients had a normal CXR and no radiological pulmonary signs $(P=0.01)$. Also, 8 HIVseropositive patients (23.52\%) had pulmonary infiltration and $3(8.82 \%)$ had a cavity versus 99 (58.23\%) and 58 (34.11\%) HIV-seronegative patients, respectively $(P=0.01$, $P=0.008$ respectively). Four (11.76\%) HIV-seropositive patients had a milliary pattern and 11 (32.35\%) had pleural effusion, compared with 10 (5.88\%) and 14 (8.23\%) HIV-seronegative patients, respectively $(P=0.05$ and $P=0.003$, respectively). In the HIV-seronegative group, 15 (8.82\%) had fibrosis and 20 patients $(11.76 \%$ ) had lymphadenopathy versus $2(5.88 \%)$ and $9(26.4 \%)$ HIV-seropositive cases, respectively $(P=0.42, P=0.23$, respectively). The location of the pulmonary manifestation on the CXR in HIV-seropositive and HIV-seronegative groups is shown in Table 1.

\section{Discussion}

Tuberculosis is an important problem in HIV-infected persons and is the leading cause of death in these patients in developing countries. In this study, we compared the radiographic findings of HIV-positive and HIV-negative patients with pulmonary tuberculosis. A normal chest radiograph was more common in the HIV-positive group. In contrast, pulmonary infiltration, cavity, and fibrosis were more frequent in HIV-negative patients, consistent with other studies, such as Kumar et al. (8), Parasad et al.(9), Haddadi et al. (10), Swaminathan et al. (11) Swaminathan et al.(11), Henna et al. (12), and Sedhain et al. (13).

The higher frequency of normal chest radiographs in the HIV-positive group may be related to decreased cellmediated immunity in these patients. Poor cell-mediated immunity results in reduced granuloma formation, caseation, liquefaction, and eventually cavitation. In contrast, the greater occurrence of cavities, fibrosis, and pulmonary infiltration in HIV-negative patients is related to the robust inflammatory response in this group. As Tripathy et al. (14) showed, cavity formation is observed in patients with higher CD4 counts, indicating that intact cell-mediated immunity is required for cavity formation. In our study, milliary pattern, hilar and mediastinal lymphadenopathy, and pleural effusion were more common in the HIV-positive group, consistent with Haddadi et al. (10), Swaminathan et al.(15), Swaminathan et al. (11), and lawn et al. (16). The more frequent occurrence of these radiographic findings may be explained by the failure of tissue containment of the disease in immunosuppressed HIV-positive patients. This finding was in contrast to Parasad et al. (9), who did not observe a significantly higher rate of milliary tuberculosis in HIV-positive patients. Pozinac et al. (17) also failed to note such a difference between HIV-positive and -negative groups, except for the higher occurrence of cavitation in HIV- 


\begin{tabular}{llll}
\hline \multicolumn{2}{l}{ Table 1. Location of Involvement in Pulmonary Tuberculosis Patients and Two Patients With HIV-Seropositive HIV- Seronegative Condition } \\
\hline Location of Involvement & HIV $^{\mathbf{a}}$-Seropositive Group, No. (\%) & HIV $^{\mathbf{a}}$-Seronegative Group, No. (\%) & P Value \\
\hline Normal CXR & a & $20(11.76)$ & 0.01 \\
Upper lobe & $11(32.35)$ & $103(60.58)$ & 0.02 \\
Middle and lower lobe & $10(29.41)$ & $47(27.64)$ & 0.22 \\
Total & $13(38.23)$ & $170(100)$ & - \\
\hline
\end{tabular}

${ }^{a}$ Abbreviations: CXR, Chest X-ray; HIV, Human Immuno deficiency Virus

negative patients. These differences might be attributed to differences in patient selection and immune status. Another cause might be racial variations in the host response to mycobacterium tuberculosis.

In our study, we observed a higher occurrence of midand lower lobe involvement in the HIV-positive group, similar to other studies, indicating poor cellular immunity in HIV-infected patients. The strength of our study is that the data are from an infectious diseases ward in Ahvaz Razi Hospital, the only referral center for HIV and tuberculosis coinfected patients.

The radiological findings of pulmonary TB differ between HIV-seropositive and HIV-seronegative patients due to poor cellular immunity in HIV-infected patients. Normal chest radiograph, milliary pattern, hilar and mediastinal lymphadenopathy, pleural effusion, and mid- and lower lobe involvement are more common in HIV-positive persons. In contrast, pulmonary infiltration, cavity, and fibrosis are more frequent in HIV-negative patients.

\section{Acknowledgment}

This paper is issued from thesis of Mr Kimyai with registration number General/111. Special thanks to Ahvaz Jundishapur University of Medical Sciences for financial support. We would also like to thank the personnel of medical archive and infectious diseases ward of Ahvaz Razi hospital for their help in this study.

\section{Funding Support}

Research Deputy, Ahvaz Jundishapur University of medical sciences.

\section{Financial Disclosure}

None delered.

\section{References}

1. Stephen J. Can your genes make you more prone to pneumococcal disease? Expert Rev Anti Infect Ther. 2010;8(9):967-72.

2. Aaron L, Saadoun D, Calatroni I, Launay O, Memain N, Vincent
$\mathrm{V}$, et al. Tuberculosis in HIV-infected patients: a comprehensive review. Clin Microbiol Infect. 2004;10(5):388-98.

3. Burzynski JN, Schluger NW. Tuberculosis and the Human Immunodeficiency Virus Infection. In: Rom WN, Garay SMe, editors. Tuberculosis. 3 rd ed. Philadelphia: Lippincott-William \& Wilkins; 2004. p. 663-81.

4. Alavi SM. Relative frequency of infections among hospitalized injecting drug user- HIV positive patients in Razi hospital, Ahvaz, SW Iran. JundishapurJ Microbiol. 2001-2003;1(1):6-9.

5. Kim JY, Jeong YJ, Kim KI, Lee IS, Park HK, Kim YD, et al. Miliary tuberculosis: a comparison of CT findings in HIV-seropositive and HIV-seronegative patients. Br J Radiol. 2010;83(987):206-11.

6. Raviglione M, O'Brien R. Tuberculosis. In: Fanci S, Braunwald E, Kasper D, editors. Harrison's principles of internal medicine. 17th ed ed; 2008. p. 1006-20.

7. F. Diagnosis of humam immunodeficiency virus infection. In: Mandell G, Bonnett JE, Dolin R, editors. Principles and practice of infectious disease. 7th ed. New York; 2010. p. 1506-27.

8. Kumar P, Sharma N, Sharma NC, Patnaik S. Clinical profile of tuberculosis in patients with HIV Infection/AIDS. Indian J Chest Dis Allied Sci. 2002;44(3):159-63.

9. Prasad R, Saini JK, Gupta R, Kannaujia RK, Sarin S, Suryakant, et al. A comparative study of clinico-radiological spectrum of tuberculosis among HIV seropositive and HIV seronegative patients. Indian J Chest Dis Allied Sci. 2004;46(2):99-103.

10. Haddadi A, Rasulnejad M, Davoodi S, Nikdel M, Rasteh M. Study of clinical manifestations of patients with pulmonary tuberculosis among HIV positive and HIV negative persons.J Tehran Uni Med Sci. 2005;5:59 - 87.

11. Swaminatan S, Sangeetha MN, Menon PA. Pulmonary tuberculosis in HIV positive individuals. Ind J chest Dis. 2002;49(186).

12. Henn L, Nagel F, Dal Pizzol F. Comparison between human immunodeficiency virus positive and negative patients with tuberculosis in Southern Brazil. Mem Inst Oswaldo Cruz.1999;94(3):377-81.

13. Sedhain A, Ramapuram JT, Adhikari P, Rao SB, Pant P, Koju RP. Clinical presentation of tuberculosis in HIV positive patients in relation to CD4 counts. JCC. 2010;1(1):30-38.

14. Tripathy S, Menon P, Joshi DR, Patil U, Gadkari DA, Paranjape RS. Preliminary observations on lymphocyte subpopulations in HIV seropositive \& HIV seronegative tuberculosis patients in Pune, India. Indian J Med Res. 2000;111:195-8.

15. Swaminatan S, Narodran G, Pradeep A, Menon C. Impact of HIV infection on radiologic features in patients with pulmonary tuberculosis. Ind J chest Dis. 2007; 49:133-6.

16. Lawn SD, Evans AJ, Sedgwick PM, Acheampong JW. Pulmonary tuberculosis: radiological features in west Africans coinfected with HIV. Br J Radiol. 1999;72(856):339-44.

17. Pozniak AL, MacLeod GA, Ndlovu D, Ross E, Mahari M, Weinberg J. Clinical and chest radiographic features of tuberculosis associated with human immunodeficiency virus in Zimbabwe. $\mathrm{Am} J$ Respir Crit Care Med. 1995;152(5 Pt 1):1558-61. 